\title{
Partial Resistance to Septoria Tritici Blotch (Mycosphaerella graminicola) in Wheat Cultivars Arina and Riband
}

\author{
L. Chartrain, P. A. Brading, J. P. Widdowson, and J. K. M. Brown
}

First author: Disease and Stress Biology Department, John Innes Centre, Norwich Research Park, Colney, Norwich NR4 7UH, UK and ENSAT, Laboratoire de Biologie et Amélioration des Plantes, Avenue de l'Agrobiopole, BP107, 31326 Castanet-Tolosan, France; second and fourth authors: Disease and Stress Biology Department, John Innes Centre, Norwich UK; and third author: Advanta Seeds UK Ltd., Station Road, Docking, King's Lynn, Norfolk PE31 8LS, UK.

Current address of L. Chartrain: School of Biological Sciences, University of East Anglia, Norwich, Norfolk NR4 7TJ, UK.

Accepted for publication 13 January 2004.

\begin{abstract}
Chartrain, L., Brading, P. A., Widdowson, J. P., and Brown, J. K. M. 2004. Partial resistance to Septoria tritici blotch (Mycosphaerella graminicola) in wheat cultivars Arina and Riband. Phytopathology 94:497-504.

Partial resistance to Septoria tritici blotch (STB) and its inheritance were investigated in a doubled-haploid population of a cross between cvs. Arina and Riband. The former has good partial resistance whereas the latter is susceptible. In adult plant trials in polytunnels, STB disease scores were negatively correlated with heading date. Resistance was not

tative trait locus (QTL) for partial resistance to STB was identified in Riband on chromosome 6B and is named QStb.psr-6B-1. No QTL controlling a major part of the Arina resistance was identified, suggesting that its resistance may be dispersed and polygenic. There was no correlation between the lines' mean disease scores at the seedling and adult stages, implying that partial resistance to STB is developmentally regulated. Seedling resistance to the isolate IPO323 was isolate-specific and controlled by a single gene in Arina, probably allelic with the $S t b 6$ gene in cv. Flame that confers resistance to the same isolate. The implications of these results for wheat breeding programs are discussed.
\end{abstract} specific to any of the three fungal isolates used in these tests. A quanti-
Septoria tritici blotch (STB), caused by the ascomycete fungus Mycosphaerella graminicola (Fuckel) Schrot., currently is the most important foliar disease of wheat in Europe and in several other regions of the world $(22,44,56)$. Fungicides are used to control STB (11) but are expensive and not fully effective. Therefore, resistant cultivars are of great value to farmers and, since the early 1980 s, breeders have attempted to select cultivars resistant to STB $(20,31)$. As with other diseases, knowledge of the genetics of resistance to STB is desirable to improve the effectiveness of breeding for resistance.

In some diseases of wheat, such as rust and powdery mildew, most resistance genes can be divided broadly into two classes: race-specific, major resistance genes and nonspecific genes for partial resistance. Extensive variation in cultivar-specific virulence of $M$. graminicola has been detected at the seedling stage $(2,21,32,33)$ and in adult plants $(8,34)$. A gene-for-gene relationship has been detected between the Dutch isolate IPO323 and the British cv. Flame, which carries the Stb6 resistance gene $(6,35)$. Stb6 resistance is expressed at both the seedling and adult stages, $(2,34)$ but it is not known if this is also the case for other isolatespecific resistances. Specific resistance might not be durable because a subset of the pathogen population may become adapted to it (12).

Partial or quantitative resistance to mildew and rust often is incomplete, isolate non-specific, and polygenic $(7,38,41,46)$. It is generally more durable than race-specific resistance and, therefore, desirable in breeding but also may be harder to select. Quantitative resistance to STB tested with natural infection was described as incomplete and polygenic by Jlibene et al. (30), Simon

Corresponding author: L. Chartrain; E-mail address: james.brown@bbsrc.ac.uk

Publication no. P-2004-0322-01R

(C) 2004 The American Phytopathological Society and Cordo (49), Zhang et al. (60), and Eriksen et al. (18). Assessment of partial resistance to STB must take into account factors other than foliar resistance itself (39) because short and earlymaturing cultivars are more susceptible than tall and late-maturing cultivars $(13,29,55)$.

In this article, the genetics of quantitative resistance to STB in F1 doubled-haploid progeny of a cross between the Swiss cv. Arina and the British cv. Riband are described. Arina is the most STB-resistant, modern European wheat cultivar known, whereas Riband is one of the most STB-susceptible cultivars (8). The study investigated whether or not partial resistance is isolate nonspecific and whether or not the same genes control resistance at the seedling and the adult stage. Molecular mapping and quantitative trait loci (QTL) analysis were used to locate a gene for quantitative resistance.

\section{MATERIALS AND METHODS}

Plant material. F1 doubled-haploid (DH) lines of a cross between Arina (Moisson/Zenith) and Riband (Norman//Maris Huntsman/TW161) were made by New Farm Crops, Ltd., using the method of Laurie and Bennett (37) with minor modifications.

Polytunnel trial. Adult plants of $70 \mathrm{DH}$ lines and both parents were tested in polytunnels at the site of Advanta Seeds UK, Ltd. (Docking, UK), in 1999 and 2000. Seven lines appeared not to be true progeny of Arina $\times$ Riband (described below) and were removed from the analysis. In 1999, there were three blocks per tunnel with 70 lines and both parents in each block; whereas, in 2000, there were four blocks per tunnel. In each block, plants were arranged in nine rows, running across the width of the tunnels, by eight ranks. Blocks were arranged end-to-end, such that there was a grid of 27 rows by eight ranks in 1999 and 36 rows by eight ranks in 2000. The layout was designed with the experimental design generator and randomizer (EDGAR, available on 
the John Innes Centre and Biotechnology and Biological Sciences Research Council [BBSRC] website). Each trial was sown in a split-plot design, with one polytunnel per isolate in each year. In each plot, five seed of one line were sown in a $7-\mathrm{cm}$ pot in a mixture of peat, perlite, and John Innes no. 3 compost. When first leaves had emerged, the plants were vernalized $\left(4^{\circ} \mathrm{C}, 12 \mathrm{~h}\right.$ of fluorescent light) for 8 weeks, and then reacclimatized at $15^{\circ} \mathrm{C}$ for 2 days. Seedlings were planted in the polytunnels in late April or early May. Tunnels were prepared with added peat and lime and compound fertilizer (N:P:K, 20:10:10) at $37.5 \mathrm{~g} \mathrm{~m}^{-2}$. Watering was from overhead sprinklers. Humidity was increased by additional watering before spraying the inoculum. Herbicide (Panther; a.i. diflufenican plus isopropuron), a mildew-specific fungicide (Fortress; a.i. quinoxyfen) and an insecticide (Permasect; a.i. permethrin) were applied as required at the manufacturer's recommended rates.

Isolates. Three $M$. graminicola isolates from the Netherlands (IPO94269, IPO89011, and IPO290) were used because they are virulent on both Arina and Riband (8). In studies with many European isolates, Riband has shown no isolate-specific resistance whereas Arina has shown resistance only to isolates that are avirulent to Stb6 (2,8; J. M. Makepeace and J. K. M. Brown, unpublished data). The isolates were grown for 5 to 7 days before inoculation both on potato dextrose agar (PDA) plates under ultraviolet light (Philips TL 20W/05) for $16 \mathrm{~h}$ per day at $15^{\circ} \mathrm{C}$ and in yeast glucose liquid media (glucose, $10 \mathrm{~g} / \mathrm{liter}$ and yeast extract, $30 \mathrm{~g} / \mathrm{liter}$ ). Both media were used because some isolates grow better on one medium than another. Spores from both media were combined and their concentration was adjusted to $4 \times$ $10^{6}$ spores $\mathrm{ml}^{-1}$. Polyoxyethylene-sorbitan monolaurate (Tween 20; Sigma-Aldrich) was added to $0.15 \%$ as a surfactant. The plants were first inoculated in June, shortly after flag leaf emergence, then again 1 week later. Spores were applied using a knapsack sprayer at a rate of $3 \times 10^{8}$ spores $\mathrm{m}^{-2}$.

Disease scoring. STB was scored as the percentage of the flag leaf area covered by lesions bearing pycnidia. Disease was scored once, when the most susceptible lines had some leaves with $90 \%$ or more disease. This was approximately 4 weeks after inoculation. Four flag leaves per plot were scored in 1999 and six in 2000. In 1999 and 2000, height was scored for one block per tunnel as the distance $(\mathrm{cm})$ from the ground to the base of the tallest ear. In 2000, heading date was scored for one block per tunnel as the date when half the ears in the plot were half emerged.

Seedling assays. Tests of responses of seedlings to M. graminicola isolates were done by spraying seedlings with fungal spores, by the method of Brading et al. (6) with minor modifications. Tests were done twice with IPO94269, once in 2000 and once in 2001, and once with IPO323 in 2001. Twelve seed of one line were sown per tray and lines were arranged in different randomized orders in the two replicates. Furthermore, the trays were moved around each week during the incubation phase to reduce position effects. Sixteen-day-old seedlings were inoculated with IPO94269 or IPO323 at a spore concentration of $1 \times 10^{7}$ spores $\mathrm{ml}^{-1}$. STB was scored as the percentage of the primary leaf covered by lesions bearing pycnidia at 21 and 28 days postinoculation (dpi); at $28 \mathrm{dpi}$, susceptible plants were highly diseased (90\% or more).

Data analysis. Factors that became apparent only during the polytunnel and seedling trials meant that the designs were unbalanced, albeit unintentionally. Therefore, data were analyzed by residual maximum likelihood (42) using the statistics program Genstat 5 for Windows (VSN International Ltd., Hemel-Hempstead, UK). The significance of fixed effects was tested by $F$ tests of Wald statistics (17). Multiple regression and principal components analysis (PCA) also were done using Genstat.

Dwarfing gene test. Arina has no known semi-dwarfing gene, whereas Riband probably inherited the gibberellic acid (GA) insensitivity gene Rht 2 from Norman (A. J. Worland, personal communication). Six seed of $63 \mathrm{DH}$ lines and both parents were screened for the presence or absence of Rht 2 using the seedling GA test of Gale and Marshall (25).

Molecular mapping. DNA from 8 to 10 16-day-old seedlings per line was extracted using a cetyltrimethylammonium bromide method (52). DNA concentration was estimated using a spectrophotometer (Ultrospec 2000; Amersham Pharmacia Biotech, Buckinghamshire, UK). Amplified fragment length polymorphism (AFLP) was detected by the method of Vos et al. (58) as described by Donini et al. (16) using the Sse83871 5'-biotin-CTCGTAGACTGCGTACATGCA-3' and MseI 5'-GACGATGAGT-

TABLE 1. Restricted maximum likelihood (REML) analysis of means over plots of logit percentage leaf area with lesions bearing pycnidia of Mycosphaerella graminicola

\begin{tabular}{|c|c|c|c|c|c|c|c|}
\hline \multirow[b]{2}{*}{ Random effects } & \multirow[b]{2}{*}{ Variance component } & \multicolumn{6}{|c|}{ Fixed effects ${ }^{\mathrm{a}}$} \\
\hline & & SE & Term & Wald statistic & df & rdf & $P^{\mathrm{b}}$ \\
\hline \multicolumn{8}{|l|}{ Term } \\
\hline \multicolumn{8}{|l|}{ Adult plants ${ }^{\mathrm{c}}$} \\
\hline Year & 0.022 & 0.049 & Row & 166.61 & 4 & 1,131 & $* * *$ \\
\hline Year $\times$ tunnel & 0.007 & 0.037 & Side & 47.32 & 1 & 1,131 & $* * *$ \\
\hline \multirow[t]{3}{*}{ Year $\times$ tunnel $\times$ block } & 0.094 & 0.035 & Line & 619.35 & 64 & 1,131 & $* * *$ \\
\hline & $\ldots$ & $\ldots$ & Isolate & 0.95 & 2 & 2 & $\mathrm{~ns}$ \\
\hline & $\ldots$ & $\ldots$ & Line $\times$ isolate & 248.83 & 128 & 131 & $* * *$ \\
\hline \multicolumn{8}{|l|}{ Seedlings, both ${ }^{\mathrm{d}}$} \\
\hline Year & 0.135 & 0.236 & Scoring date & 237.14 & 1 & 115 & $* * *$ \\
\hline \multirow[t]{6}{*}{ Scorer } & 0.190 & 0.379 & Line & 501.08 & 65 & 115 & $* * *$ \\
\hline & $\ldots$ & $\ldots$ & Isolate & 141.30 & 1 & 1 & $*$ \\
\hline & $\ldots$ & $\ldots$ & Date $\times$ line & 21.28 & 65 & 115 & ns \\
\hline & $\ldots$ & $\ldots$ & Line $\times$ isolate & 658.67 & 64 & 115 & $* * *$ \\
\hline & $\ldots$ & $\ldots$ & Date $\times$ isolate & 57.35 & 1 & 115 & $* * *$ \\
\hline & $\ldots$ & $\ldots$ & Date $\times$ line $\times$ isolate & 15.89 & 64 & 115 & ns \\
\hline \multicolumn{8}{|l|}{ Seedlings, one $\mathrm{e}^{\mathrm{e}}$} \\
\hline Year & 0.026 & 0.382 & Date & 742.31 & 1 & 2,726 & $* * *$ \\
\hline \multirow[t]{2}{*}{ Scorer } & 0.096 & 0.140 & Line & 500.48 & 65 & 2,726 & $* * *$ \\
\hline & $\ldots$ & $\ldots$ & Date $\times$ line & 424.44 & 65 & 2,726 & $* * *$ \\
\hline
\end{tabular}

a $\mathrm{SE}=$ standard error, $\mathrm{df}=$ degrees of freedom, $\mathrm{rdf}=$ residual degrees of freedom.

${ }^{\mathrm{b}} P=$ significance of Wald statistics $(F$ test) $(17) ; *=0.05 \geq P>0.01, * * *=0.001 \geq P$, and $\mathrm{ns}=P>0.05$.

c Polytunnel trial of adult plants.

d Seedling trials for isolates IPO323 and IPO94269.

e Seedlings trials, data for isolate IPO94269 only. 
CCTGAG-3' adapters and the Sse +2 and $\mathrm{Mse}+2$ primers. Each gel was scored at least twice by two different people. Microsatellite markers were analyzed as described by Bryan et al. (9). Most of the markers were obtained from the Institute of Plant Genetics and Crop Plant Research (IPK), Gatersleben, UK (47). The other markers were provided by the John Innes Centre, Norwich, UK (51).

Linkage mapping and QTL analysis. Genetic mapping was done using JoinMap (version 2.0; Plant Research International, Wageningen, The Netherlands). Linkage groups were formed at a log-likelihood (LOD) threshold of 5. Recombination fractions were converted to map distances using the Kosambi (36) function. Output from JoinMap was converted to a graphical format using the program MapChart (Plant Research International). QTL analysis was done using MapQTL (version 4.0; Plant Research International) by interval mapping and multiple QTL mapping (MQM) $(27,28)$.

\section{RESULTS}

Polytunnel trials. The position of the plants in the polytunnel appeared to affect disease development because the two rows nearest the ends of each tunnel were less infected than other rows, as were plants in the ranks next to the sides of each tunnel. Two factors, "side" and "row", therefore were introduced into the statistical analysis. The side factor contrasted plants at the sides of the tunnel with those in the middle six ranks. The row factor had five levels: the rows nearest and next nearest to the north end of the tunnel, nearest and next nearest to the south end, and the remaining 23 rows in 1999 and 32 rows in 2000.

The mean logit-transformed disease score was calculated for each plot. The position of the plot within the tunnel was important, because plots located on the sides or at the ends of the tunnel tended to be less heavily diseased, as suspected (Table 1, adult plants). A large effect of the row factor was identified (Table 1, adult plants), but this only concerned 4 rows out of 27 or 36 in each tunnel (1999 or 2000, respectively) and, therefore, affected only a small proportion of the data. The effect of the side factor

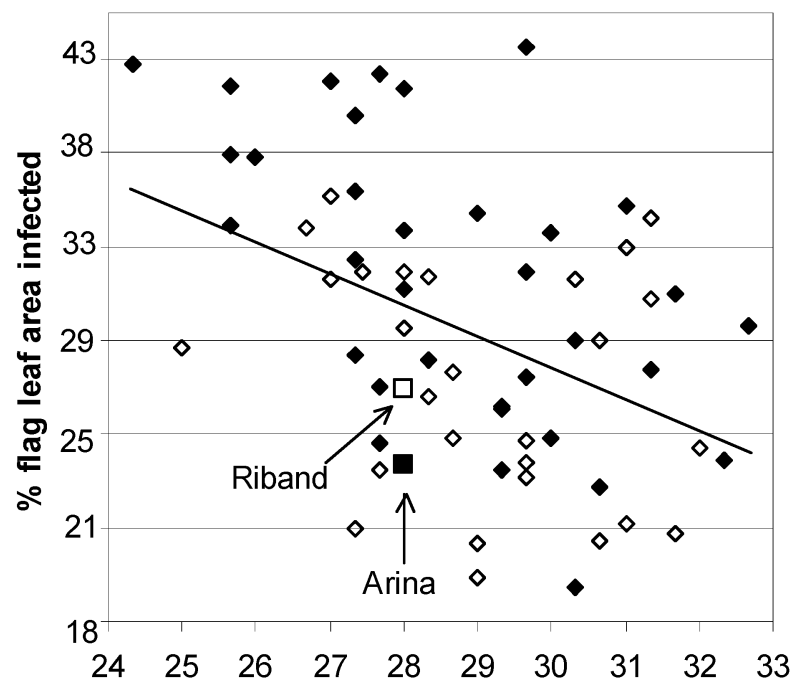

Heading date (days from 1st May)

\section{Allele of StaMct.200A $\diamond$ Arina $\diamond$ Riband}

Fig. 1. Percentage of flag leaf area diseased by Septoria tritici blotch in the adult plant experiment, plotted against heading date. Lines are classified by Arina and Riband alleles of the amplified fragment length polymorphism marker StaMct.200A. The axis showing disease scores is plotted on a logit scale. was small. Therefore, the lack of balance of the design, caused by the row and side effects, did not substantially affect the conclusions of the experiment.

There was a wide range of variation in disease scores among the lines. In all, $41 \mathrm{DH}$ lines were more susceptible than Riband and 11 lines were more resistant than Arina (Fig. 1), indicating transgressive segregation of resistance and susceptibility. There was no difference between the mean responses to each isolate because each tunnel was scored at a chosen time, when susceptible plants were highly diseased.

Mean logit STB scores for the lines estimated by restricted maximum likelihood (REML) means were negatively correlated with heading date $(R=-0.43 ; P<0.001)$ (Fig. 1$)$ but positively correlated with height $(R=0.33 ; P=0.008)$. There also was a negative correlation between heading date and height $(R=-0.53$; $P<0.001)$. Once the effect of heading date was removed, there was no partial correlation between height and STB $(R=0.13 ; P=$ 0.3 ). After multiple regression on heading date and plant height, only 5 lines were more resistant than Arina and 42 lines were more susceptible than Riband (mean over isolates) (data not shown). This emphasizes the high level of partial resistance of Arina to STB but indicates transgressive segregation of susceptibility, implying that Riband has one or more resistance genes, despite being susceptible in UK field conditions.

REML analysis detected slight but significant variation in the responses of the lines to the three different isolates. However, in PCA of the REML means for lines and isolates, the first principal component (PC1) accounted for $72 \%$ of the total variation and responses to all three isolates contributed equally to PC1 (Table 2 ). The smallest two PCs did not account for significant proportion of the total variation. This indicates that variation in responses to the three isolates was minor compared with the main effect of non-specific resistance to all three isolates.

The repeatability between years of mean STB scores for the lines (across isolates) was high (correlation coefficient of means in 1999 and 2000; $R_{y}=74 \%$ ) (Fig. 2). This implies that partial resistance is highly heritable in this cross under the test conditions used. The lines tested were fully homozygous doubled haploids; therefore, $R_{y}$ is effectively an estimate of narrow-sense heritability and of the predicted response to selection.

Seedling tests. The mean logit STB scores per plot (i.e., per tray) were calculated. There were significant differences between mean disease scores on the two dates of scoring and between isolates (Table 1, both seedlings). There also was an interaction between the date of scoring and the isolate because the two isolates had different latent periods of infection. Isolate-specific resistance to IPO323 segregated in this cross; therefore, quantitative resistance was studied in response to IPO94269.

Arina has isolate-specific resistance to IPO323 $(2,8)$ whereas Riband is susceptible to this isolate (8). Of the $63 \mathrm{DH}$ lines, 29 had less than $1 \%$ disease and 28 lines had more than 50\% disease, while six lines had intermediate mean scores (Fig. 3). Whether the intermediate lines are pooled with the susceptible or resistant lines, the segregation ratio was not significantly different from the

TABLE 2. Principal component analysis of logit mean levels of Septoria tritici blotch caused by three isolates of Mycosphaerella graminicola on wheat doubled-haploid progeny lines

\begin{tabular}{lccc}
\hline & \multicolumn{3}{c}{ Principal component $^{\mathrm{a}}$} \\
\cline { 2 - 4 } & 1 & 2 & 3 \\
\hline Percent variation & $72^{* * *}$ & $16 \mathrm{~ns}$ & 12 \\
Loading of isolates & & & 0.66 \\
IPO290 & -0.58 & 0.48 & 0.10 \\
IPO89011 & -0.56 & -0.82 & -0.75 \\
IPO94269 & -0.59 & 0.31 & \\
\hline a $* * *$ = Significantly larger than PC2 and PC3 $\left(\chi^{2}=65,5 \mathrm{df}, P<10^{-11}\right) ; \mathrm{ns}=$
\end{tabular}
not significantly larger than PC3 $\left(\chi^{2}=1.2,2 \mathrm{df}, P=0.6\right)$. 
1:1 segregation ratio expected for a single gene in a $\mathrm{DH}$ population. To determine whether or not Arina is likely to carry Stb6, which confers specific resistance to IPO323, microsatellite analysis was done with the marker WMS369, which maps to the locus Xgwm369 (47) and is closely linked to Stb6 in Flame (6). In all, 24 of the resistant lines had the same allele as Arina and 25 of the susceptible lines had the Riband allele. Out of 57 lines, 6 clearly classified as resistant or susceptible to IPO323 were recombinant, whereas 2 lines could not be scored for the Xgwm369 allele. The six lines with intermediate mean scores all had the Riband allele. If the intermediate lines are pooled with the susceptible lines, the recombination fraction (10\%) between Stb6 and Xgwm369 is larger than the estimate of $2 \%$ (6) but the two estimates are not significantly different $(P>0.05)$.

Differences between the mean disease scores of lines infected with IPO94269 were statistically significant (Table 1, one seedling) but relatively small. As in the adult stage, Arina was not the most resistant line and Riband was not the most susceptible, indicating transgressive segregation of resistance and susceptibility.



\% flag leaf area infected in 1999

- Arina $\square$ Riband

Fig. 2. Percentage of flag leaf area diseased by Septoria tritici blotch in the adult plant experiments in 1999 ( $x$ axis) and 2000 ( $y$ axis). Axes are plotted on a logit scale.



Fig. 3. Mean percent disease scores of seedlings inoculated with Mycosphaerella graminicola isolates IPO323 and IPO94269. The axes are plotted on a logit scale.
Disease scores of the seedlings inoculated with IPO94269 were compared with REML means of adult plants with IPO94269 (Fig. 4) and with those with all three isolates together. There was no significant correlation between seedling and adult means for the 63 lines, implying that different genes control resistance at the seedling and adult stages.

Dwarfing gene test. Of 63 lines in the dwarfing gene test, 27 were sensitive to GA, 37 were insensitive, and 1 had an intermediate phenotype; the 27:37 segregation was not significantly different from a $1: 1$ ratio $\left(\chi^{2}=0.8 ; P=0.38\right)$. This is consistent with Riband having one Rht gene, probably Rht 2 inherited from Norman. There was no significant difference between the GAsensitive and insensitive lines in response to STB, estimated as the residuals from multiple regression of REML mean STB scores on height and heading date.

Molecular mapping. In all, 225 AFLP primer pairs were screened against Arina and Riband. Sixty-five pairs, which produced at least 10 polymorphic bands, then were screened against $63 \mathrm{DH}$ lines. The 374 AFLP markers used in mapping excluded those with a distorted segregation $(P \leq 0.001)$. In all, 110 microsatellite markers were tested against the parents to anchor AFLP markers to chromosomes, and 34 polymorphic microsatellite markers then were used in mapping.

Seven lines had AFLP patterns different from those of Arina and Riband, implying they were not true progeny of the cross. These lines were removed from the analysis of disease data.

Markers potentially linked to resistance were identified by Student's $t$ test. The residuals from multiple regression of the STB REML means on heading date and height were calculated as a measure of disease susceptibility independent of plant development and morphology (55). For each marker, the mean of these residuals for lines with the band was compared with the mean of those lacking the band. Markers were considered to be significantly associated with resistance when the $t$ test probability was less than $1 / 374=0.0027$. Nine AFLP markers and one microsatellite were found to be linked to resistance in this way (Table 3). The most strongly linked marker was StaMct.200A (i.e., the band was present in Arina). Nine markers, including the microsatellite marker $X g w m 133$, were included in the same linkage group of 40 markers formed at $\mathrm{LOD} \geq 5$. One marker, SagMta.132A, mapped to a different group at LOD $\geq 5$. Microsatellite markers on the group of 40 markers (Xgwm133 and

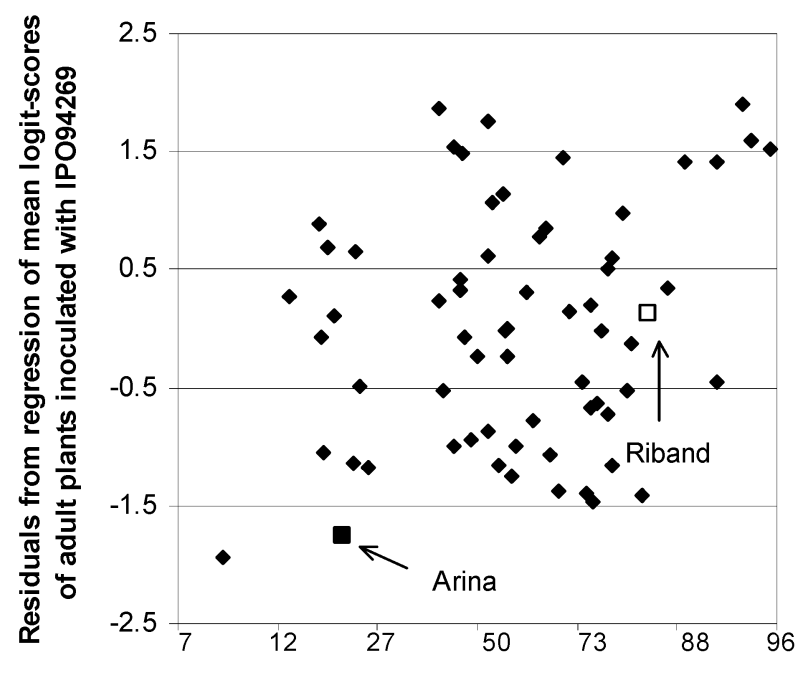

Mean \% disease of seedlings with IPO94269

Fig. 4. Residuals of logit scores regressed on heading date and height for adult plants infected with Mycosphaerella graminicola isolate IPO94269, plotted against mean percent disease of seedlings inoculated with isolate IPO94269. 
Xgwm219) allowed it to be located to chromosome 6B (47). Eleven markers, including one of those linked to resistance (SatMaa.178R), were discarded during the mapping process because they caused significant $(P \leq 0.05)$ distortion of the map; this was probably because missing data caused inconsistent estimates of recombination fractions. The final partial map of chromosome 6B included 29 markers and covered 87 centimorgans (Fig. 5). For all loci linked to resistance, the allele linked in coupling to resistance was that of Riband, implying that the resistance gene came from Riband, not Arina.

The QTL analysis on this group was first done using interval mapping to identify possible QTL. One QTL was detected close to the StaMct.200A locus. Therefore, this marker was used as a cofactor in MQM, which confirmed that only one QTL segregated in this region $(P=0.001$ by interpolation of values for a genomewide test of significance of QTL effects) (57). This QTL had a LOD score of 3.74 and accounted for $24 \%$ of the residual variance (Fig. 6). There was a tendency for the resistant DH lines to carry the Riband allele for StaMct.200A (Fig. 1), which also suggests that the resistance gene is closely linked to this marker.

The association of StaMct.200A with seedling resistance was tested. For seedlings inoculated with IPO94269, the STB logit means of lines with the Arina allele were compared with those with the Riband allele. There was no correlation between the allele of the AFLP marker and infection levels at the seedling stage (Student's $t$ test; $P=0.2$ ), implying that the QTL identified here is only effective at the adult plant stage.

\section{DISCUSSION}

The aim of the experiments reported here was to characterize partial resistance to STB. The work used defined isolates of M. graminicola to study partial resistance to STB, which allowed us to address the question of isolate specificity of partial resistance. The effect of heading date and height on partial resistance also were investigated. We were also able to identify a region of the genome that controls partial resistance to STB, although the work did not intend to establish a comprehensive map of the cross.

Tests of adult plants showed clear variation in mean disease levels among progeny lines, which was substantially isolate-nonspecific. A small interaction between line and isolate was detected by REML analysis but this was a much smaller effect than the main effect of isolate non-specific resistance. PCA found approxi-

TABLE 3. Summary of $t$ test analysis of association of amplified fragment length polymorphism (AFLP) and microsatellite markers with Septoria tritici blotch $(\mathrm{STB})$ resistance ${ }^{\mathrm{a}}$

\begin{tabular}{lrcc}
\hline Marker & Diff & edf & $P$ \\
\hline SacMct.140R & -0.91 & 58 & $2 \times 10^{-4}$ \\
SagMta.132A & 0.78 & 50 & $2 \times 10^{-3}$ \\
SatMaa.178R & -0.81 & 58 & $1 \times 10^{-3}$ \\
SatMac.235R & -0.89 & 56 & $3 \times 10^{-4}$ \\
SatMac.400R & -0.77 & 56 & $2 \times 10^{-3}$ \\
SccMgc.130A & 0.77 & 58 & $2 \times 10^{-3}$ \\
SccMgc.380A & 0.90 & 54 & $4 \times 10^{-4}$ \\
SgtMat.95A & 0.81 & 58 & $1 \times 10^{-3}$ \\
StaMct.200A & 1.06 & 51 & $3 \times 10^{-5}$ \\
Xwgm133 & 0.83 & 61 & $5 \times 10^{-4}$ \\
\hline
\end{tabular}

a Only markers with a $t$ test probability less than 0.0027 ( 1 over 374 AFLP markers used in the mapping) are listed. For AFLP markers, the letters following $\mathrm{S}$ and $\mathrm{M}$ indicate the sequence of selective bases in the primer and the number indicates the approximate size of the band. The final letter indicates whether the AFLP band is present in Arina (A) or Riband (R). Diff $=$ difference of mean scores between lines with the band and those lacking the band. The variable analyzed was the residual from multiple regression of mean STB logit-scores, estimated by restricted maximum likelihood, on heading date and height. edf $=$ effective degrees of freedom. $P=$ probability associated with the $t$ statistic. mately equal contributions of the three isolates to $\mathrm{PC} 1$, indicating that the lines responded similarly to the three isolates. The significance of the line-isolate interaction in the REML is the result of the large number of data obtained at the plot level, whereas the PCA estimates the interaction at the line level, which is more relevant to assessment of isolate nonspecificity of partial resistance of wheat genotypes or cultivars.

Quantitative studies of STB must take account of the effect of plant architecture and development on the disease (39). Here, there was a significant negative correlation between flowering time and STB infection, as reported previously $(1,19,24)$. A possible explanation is that leaves of earlier-heading plants were more fully expanded when sprayed and, therefore, received more inoculum. In several studies, height has been negatively correlated with STB $(48,53)$. This was not the case in our experiments. The correlation between height and STB infection was positive but was not significant once the correlation between heading date and STB was accounted for. $M$. graminicola inoculum was applied by spraying from above; therefore, it is likely that the height of the plants did not affect the density of inoculation, hence the absence of a significant partial correlation between STB and height.

Baltazar et al. (3) reported that cultivars carrying the GA insensitivity gene Rht 2 tended to be more resistant to STB than cultivars carrying another GA insensitivity gene, Rhtl. The resistant

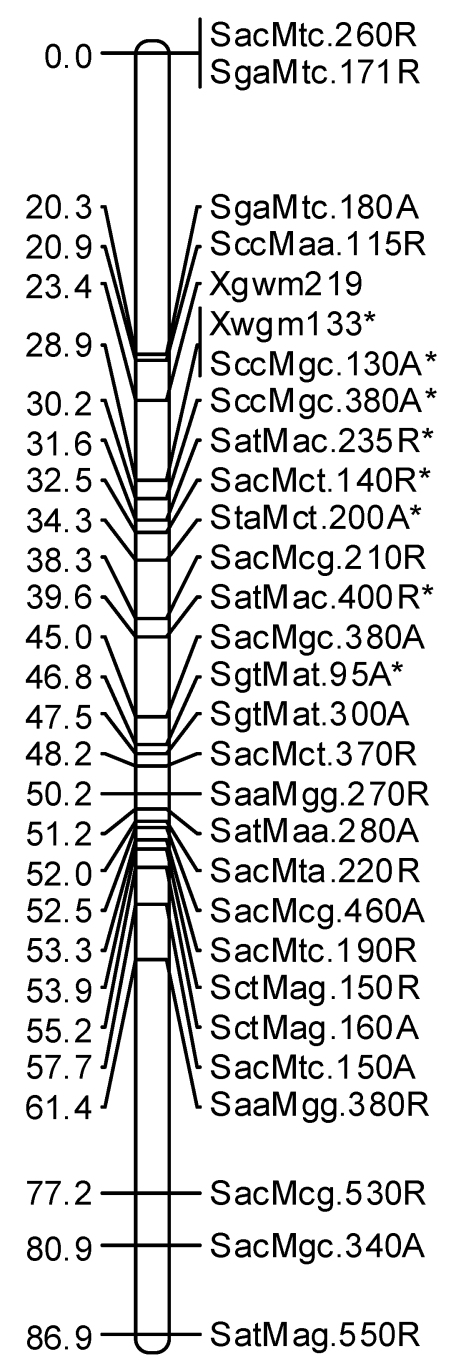

Fig. 5. Molecular marker map of part of chromosome $6 \mathrm{~B}$ in Arina $\times$ Riband. Kosambi map distances are on the left of the chromosome. The letter A or R indicates whether the amplified fragment length polymorphism band is present in Arina (A) or Riband (R). The star indicates that the marker is significantly linked to Septoria tritici blotch resistance (Table 2). 
parent, Arina, is taller than Riband and, from the pedigree, it was suspected that Arina had neither Rht1 nor Rht2 and that Riband carries Rht2 (A. J. Worland, personal communication). The GA sensitivity test confirmed the presence of an Rht gene in Riband but there was no evidence for correlation between the presence of the Rht gene and resistance to STB.

Polygenic resistance to STB has been studied by diallel analysis $(30,60)$ but no gene was identified. The interpretation of the results of these experiments is somewhat problematical because the progeny were trialed in the field and, therefore, exposed to natural infection, presumably by many pathogen genotypes. Quantitative resistance identified in these experiments may have included a component of specific resistance. The protocols used here allowed isolate-specific and non-specific partial resistances to STB to be studied separately, apparently for the first time.

In our experiment, 11 markers out of 484 screened appeared to be linked to resistance, 9 of which mapped to chromosome $6 \mathrm{~B}$. The resistance allele came from Riband, which was unexpected because Riband was chosen for its susceptibility to STB. A QTL segregated in this region close to the StaMct.200A locus and accounted for $24 \%$ of the phenotypic variation, showing the presence of a quantitative resistance gene named QStb.psr-6B-1 in Riband.

It is not at all unusual for the more susceptible parent of a cross to contribute alleles for increased resistance to diverse diseases and pests of many crops $(10,14,15,43,54)$. This may lead to transgressive segregation, with progeny lines that combine resistance genes from both parents and hence have better resistance than either parent (Fig. 1).

Tests with seedlings have been used to assess STB disease severity $(1,23,34)$. Arraiano et al. (2) distinguished specific resistance, which appears not to depend on growth stage, and quantitative resistance, which does. The seedling response to IPO94269 was compared with the adult response to the same isolate and with the mean adult response to the three isolates. In these experiments, no correlation between disease levels on seedlings and on adult plants was detected, indicating that different genes control partial resistance at the two stages This implies that partial resistance can be assessed accurately only in plant breeding trials

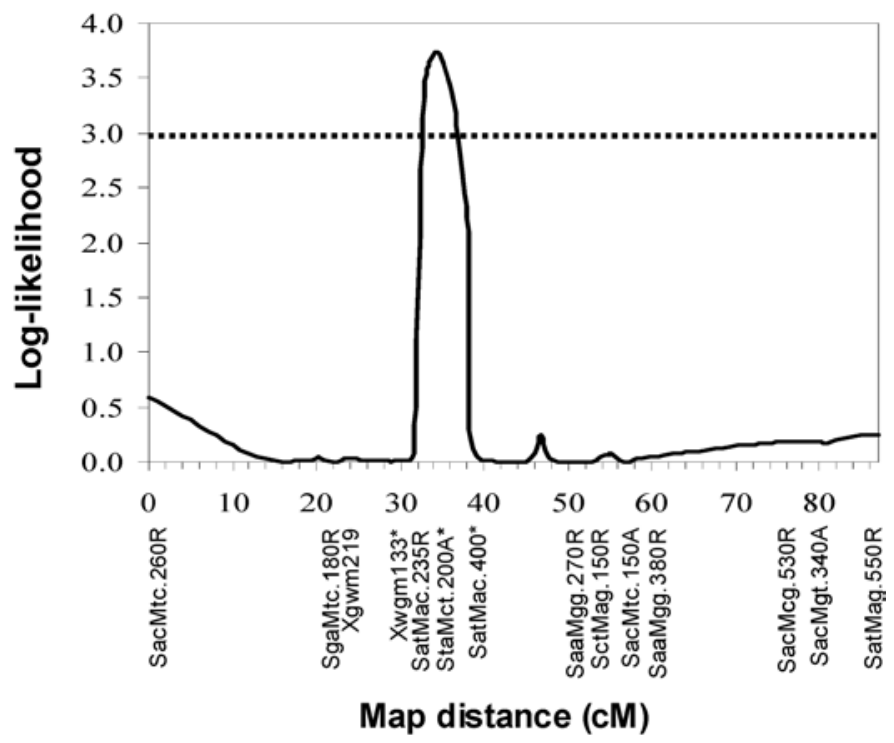

Fig. 6. Location of quantitative trait loci (QTL) for partial resistance to Septoria tritici blotch (STB) detected by MQM mapping on chromosome 6B of Arina $\times$ Riband. The dotted line indicates the $5 \%$ significance threshold log-likelihood score for genome-wide identification of QTL (57). The letter A or $\mathrm{R}$ indicates whether the amplified fragment length polymorphism band is present in Arina (A) or Riband (R); $\mathrm{cM}=$ centimorgan. The star indicates that the marker is significantly linked to STB resistance (Table 2). Only selected markers are shown. of adult plants, as with mildew (26), brown or leaf rust (45), and yellow (stripe) rust $(4,31,50)$.

Inoculation of seedlings with IPO323 showed segregation of the DH lines in a 1:1 ratio, consistent with Arina carrying a gene for specific resistance to IPO323. Linkage of the resistance gene to the microsatellite locus $\mathrm{Xgwm} 369$ indicated that this gene is probably Stb6, which confers resistance of Flame to the same isolate. The possibilities that the gene in Arina is closely linked to Stb6 or is a different allele at the Stb6 locus from that of Flame cannot be excluded. The Stb6-like gene in Arina had no effect on STB levels in adult plants because the three isolates used were all virulent to $\operatorname{Stb6}(2,8)$.

No QTL for resistance could be identified in Arina. This is partly because only a moderate number of lines, 63, were used; therefore, small QTL effects would not have been detected. Inspection of Table 3 of van Ooijen (57) suggests that QTLs with a LOD score less than about 2 would not have been declared significant $(P<0.05)$. Nevertheless, the facts that a QTL controlling more than $24 \%$ of phenotypic variation was identified in Riband and that Arina is much more resistant than Riband imply that Arina may have several resistance genes with comparatively small effects dispersed across chromosomes; it is not possible to determine how many such genes there are, but they confer partial resistance at least to the three isolates tested in this experiment. Segregation of these genes and of QStb.psr-6B-1 explains the transgressive segregation of resistance and susceptibility that appeared in both seedling and adult plant experiments, in which Riband was not the most susceptible line and Arina was not the most resistant.

In a QTL study (18), partial resistance to STB in the field was scored following inoculation with a mixture of 11 virulent isolates. Two QTL for field resistance to STB were identified, one of which, Qstb.ris $\phi-6 B .2$, mapped to chromosome 6B, close to the centromere. This QTL explained a high proportion of the phenotypic variation in the field and also was effective at the seedling stage. It is unlikely that Qstb.psr-6B.1 and Qstb.ris $\phi-6 B .2$ are the same gene. First, Qstb.ris $\phi-6 B .2$ explained a much higher proportion $(68 \%)$ of the phenotypic variation than Qstb.psr-6B.1 did. Second, Qstb.ris $\phi-6 B .2$ was effective at both seedling and adult stages. Third, Qstb.ris $\phi-6 B .2$ may be isolate specific because it was effective against one of the two isolates tested on seedlings but not the other. It is possible, therefore, that Qstb.ris $\phi-6 B .2$ is a major gene conferring isolate-specific resistance rather than a partial-resistance gene. The two maps of chromosome 6B in this article and in the study by Eriksen et al. (18) cannot yet be compared, because the microsatellite markers used were different.

The results reported in this article have implications for methods of breeding for resistance to STB. On the one hand, markerassisted selection (MAS) of the partial resistance gene at the QStb.psr-6B-1 locus would only raise STB resistance to a mean level similar to that of Riband, the minimum acceptable in the United Kingdom. On the other hand, it is unlikely to be commercially worthwhile to use MAS to select several QTL with smaller effect from Arina. If this situation exists in other partially resistant cultivars (8), then breeders should emphasize improving methods of trialing lines for responses to STB, rather than relying on MAS. However, MAS for identified QTLs could be combined with improved methods of disease testing to produce commercial lines with resistance similar or superior to that of Arina.

Three other conclusions from this paper are relevant to selection of STB-resistance. First, partial resistance to STB should be tested at the adult-plant stage because, in this study, it was not correlated with partial, isolate-nonspecific resistance in seedlings (Fig. 4). Second, the negative correlation of STB scores and heading date confirms previous results $(1,29,55)$. Third, the substantially isolate-nonspecific nature of partial resistance (Table 2) implies that, as with powdery mildew and rust, it is likely to be durable $(5,40,59,61)$. 


\section{ACKNOWLEDGMENTS}

This research was funded by the European Union's Framework IV Biotechnology program and the Department for Environment, Food and Rural Affairs for England (DEFRA). We thank New Farm Crops, Ltd., for providing the doubled-haploid lines and F. Cantin and F. Tessadori for help with the AFLP mapping.

\section{LITERATURE CITED}

1. Arama, P. F., Parlevliet, J. E., and Van Silfhout, C. H. 1999. Heading date and resistance to Septoria tritici blotch in wheat not genetically associated. Euphytica 106:63-68.

2. Arraiano, L. S., Brading, P. A., and Brown, J. K. M. 2001. A detached seedling leaf technique to study resistance to Mycosphaerella graminicola (anamorph Septoria tritici) in wheat. Plant Pathol. 50:339-346.

3. Baltazar, B. M., Scharen, A. L., and Kronstad, W. E. 1990. Association between dwarfing genes Rhtl and Rht 2 and resistance to Septoria tritici blotch in winter wheat (Triticum aestivum L. Em Thell). Theor. Appl. Genet. 79:422-426.

4. Bariana, H. S., and McIntosh, R. A. 1995. Genetics of adult plant stripe rust resistance in four Australian wheats and the French cultivar 'Hybride-de-Bersee'. Plant Breed. 114:485-491.

5. Bennett, F. G. A. 1984. Resistance to powdery mildew in wheat-A review of its use in agriculture and breeding programs. Plant Pathol. 33:279-300.

6. Brading, P. A., Verstappen, E. C. P., Kema, G. H. J., and Brown, J. K. M. 2002. A gene-for-gene relationship between wheat and Mycosphaerella graminicola, the Septoria tritici blotch pathogen. Phytopathology 92:439445 .

7. Broers, L. H. M., Subias, X. C., and Atilano, R. M. L. 1996. Field assessment of quantitative resistance to yellow rust in ten spring bread wheat cultivars. Euphytica 90:9-16.

8. Brown, J. K. M., Kema, G. H. J., Forrer, H. R., Verstappen, E. C. P., Arraiano, L. S., Brading, P. A., Foster, E. M., Fried, P. M., and Jenny, E. 2001. Resistance of wheat cultivars and breeding lines to Septoria tritici blotch caused by isolates of Mycosphaerella graminicola in field trials. Plant Pathol. 50:325-338.

9. Bryan, G. J., Collins, A. J., Stephenson, P., Orry, A., Smith, J. B., and Gale, M. D. 1997. Isolation and characterisation of microsatellites from hexaploid bread wheat. Theor. Appl. Genet. 94:557-563.

10. Cherif, M., and Harrabi, M. 1993. Transgressive segregation for resistance to Pyrenophora teres in barley. Plant Pathol. 42:617-621.

11. Cook, R. J., Hims, M. J., and Vaughan, T. B. 1999. Effects of fungicide spray timing on winter wheat disease control. Plant Pathol. 48:33-50.

12. Cowger, C., Hoffer, M. E., and Mundt, C. C. 2000. Specific adaptation by Mycosphaerella graminicola to a resistant wheat cultivar. Plant Pathol. 49:445-451.

13. Danon, T., Sacks, J. M., and Eyal, Z. 1982. The relationships among plant stature, maturity class, and susceptibility to Septoria leaf blotch of wheat. Phytopathology 72:1037-1042.

14. Dirlewanger, E., Isaac, P. G., Ranade, S., Belajouza, M., Cousin, R., and Devienne, D. 1994. Restriction fragment length polymorphism analysis of loci associated with disease resistance genes and developmental traits in Pisum sativum L. Theor. Appl. Genet. 88:17-27.

15. Dixon, A. G. O., Bramelcox, P. J., and Harvey, T. L. 1991. Complementarity of genes for resistance to greenbug Schizaphis graminum (Rondani), biotype-E, in sorghum Sorghum bicolor (L.) Moench. Theor. Appl. Genet. 81:105-110.

16. Donini, P., Elias, M. L., Bougourd, S. M., and Koebner, R. M. D. 1997. AFLP fingerprinting reveals pattern differences between template DNA extracted from different plant organs. Genome 40:521-526.

17. Elston, D. A.1998. Estimation of denominator degrees of freedom of Fdistributions for assessing Wald statistics for fixed-effect factors in unbalanced mixed models. Biometrics 54:1085-1096.

18. Eriksen, L., Borum, F., and Jahoor, A. 2003. Inheritance and location of resistance to Mycosphaerella graminicola causing Septoria tritici blotch and plant height in the wheat (Triticum aestivum L.) genome with DNA markers. Theor. Appl. Genet. 107:515-527.

19. Eyal, Z. 1981. Integrated control of Septoria diseases of wheat. Plant Dis. 65:763-768

20. Eyal, Z. 1999. The Septoria tritici and Stagonospora nodorum blotch diseases of wheat. Eur. J. Plant Pathol. 105:629-641

21. Eyal, Z., Amiri, Z., and Wahl, L. 1973. Physiologic specialization of Septoria tritici. Phytopathology 63:1087-1091.

22. Eyal, Z., and Levy, E. 1987. Variations in pathogenicity patterns of Mycosphaerella graminicola within Triticum spp. in Israel. Euphytica 36:237-250.

23. Eyal, Z., Scharen, A. L., Huffman, M. D., and Prescott, J. M. 1985. Global insights into virulence frequencies of Mycosphaerella graminicola. Phytopathology 75:1456-1462.
24. Eyal, Z., and Talpaz, H. 1990. The combined effect of plant stature and maturity on the response of wheat and triticale accessions to Septoria tritici. Euphytica 46:133-141.

25. Gale, M. D., and Marshall, G. A. 1975. The nature and genetic control of gibberellic insensitivity in dwarf wheat grain. Heredity 35:55-56.

26. Hague, R. E., and Brown, J. K. M.1996. Molecular biometrical genetics of powdery mildew resistance in wheat. Pages 204-207 in: Proc. 9th Eur. Mediterr. Cereal Rusts and Powdery Mildews Conf. Lunteren, The Netherlands.

27. Jansen, R. C. 1993. Interval mapping of multiple quantitative trait loci. Genetics 135:205-211.

28. Jansen, R. C. 1994. Controlling the type-I and type-II errors in mapping quantitative trait loci. Genetics 138:871-881.

29. Jlibene, M., Gustafson, J. P., and Rajaram, S. 1992. A field disease evaluation method for selecting wheats resistant to Mycosphaerella graminicola. Plant Breed. 108:26-32.

30. Jlibene, M., Gustafson, J. P., and Rajaram, S. 1994. Inheritance of resistance to Mycosphaerella graminicola in hexaploid wheat. Plant Breed. 112:301-310.

31. Johnson, R. 1992. Past, present and future opportunities in breeding for disease resistance, with examples from wheat. Euphytica 63:3-22.

32. Kema, G. H. J., Annone, J. G., Sayoud, R., Van Silfhout, C. H., Van Ginkel, M., and Debree, J. 1996. Genetic variation for virulence and resistance in the wheat-Mycosphaerella graminicola pathosystem. 1. Interactions between pathogen isolates and host cultivars. Phytopathology 86:200-212.

33. Kema, G. H. J., Sayoud, R., Annone, J. G., and Van Silfhout, C. H. 1996. Genetic variation for virulence and resistance in the wheatMycosphaerella graminicola pathosystem. 2. Analysis of interactions between pathogen isolates and host cultivars. Phytopathology 86: 213-220.

34. Kema, G. H. J., and Van Silfhout, C. H. 1997. Genetic variation for virulence and resistance in the wheat Mycosphaerella graminicola pathosystem. 3. Comparative seedling and adult plant experiments. Phytopathology 87:266-272.

35. Kema, G. H. J., Verstappen, E. C. P., and Waalwijk, G. 2000. Avirulence in the wheat Septoria tritici leaf blotch fungus Mycosphaerella graminicola is controlled by a single locus. Mol. Plant-Microbe Interact. 13: 1375-1379.

36. Kosambi, D. D. 1944. The estimation of map distances from recombination values. Ann. Eugen. 12:172-175.

37. Laurie, D. A., and Bennett, M. D. 1986. Wheat $\times$ maize hybridization. Can. J. Genet. Cytol. 28:313-316.

38. Liu, S. X., Griffey, C. A., and Maroof, M. A. S. 2001. Identification of molecular markers associated with adult plant resistance to powdery mildew in common wheat cultivar Massey. Crop Sci. 41:1268-1275.

39. Lovell, D. J., Parker, S. R., Hunter, T., Royle, D. J., and Coker, R. R. 1997. Influence of crop growth and structure on the risk of epidemics by Mycosphaerella graminicola (Septoria tritici) in winter wheat. Plant Pathol. 46:126-138.

40. Messmer, M. M., Seyfarth, R., Keller, M., Schachermayr, G., Winzeler, M., Zanetti, S., Feuillet, C., and Keller, B. 2000. Genetic analysis of durable leaf rust resistance in winter wheat. Theor. Appl. Genet. 100:419431.

41. Parlevliet, J. E. 1993. What is durable resistance, a general outline. Pages 23-39 in: Durability of Disease Resistance. T. H. Jacobs and J. E. Parlevliet, eds. Kluwer Academic Publishers, The Netherlands.

42. Patterson, H. D., and Thomson, R. 1971. Recovery of inter-block information when block sizes are unequal. Biometrika 58:545-554.

43. Pernet, A., Hoisington, D., Dintinger, J., Jewell, D., Jiang, C., Khairallah, M., Letourmy, P., Marchand, J. L., Glaszmann, J. C., and De Leon, D. G. 1999. Genetic mapping of maize streak virus resistance from the Mascarene source. II. Resistance in line CIRAD390 and stability across germplasm. Theor. Appl. Genet. 99:540-553.

44. Polley, R. W., and Thomas, M. R. 1991. Surveys of diseases of winter wheat in England and Wales, 1976-1988. Ann. Appl. Biol. 119:1-20.

45. Qi, X., Jiang, G., Chen, W., Niks, R. E., Stam, P., and Lindhout, P. 1999. Isolate-specific QTLs for partial resistance to Puccinia hordei in barley. Theor. Appl. Genet. 99:877-884.

46. Qi, X. Q., Fufa, F., Sijtsma, D., Niks, R. E., Lindhout, P., and Stam, P. 2000. The evidence for abundance of QTLs for partial resistance to Puccinia hordei on the barley genome. Mol. Breed. 6:1-9.

47. Röder, M. S., Korzun, V., Wendehake, K., Plaschke, J., Tixier, M. H., Leroy, P., and Ganal, M. W. 1998. A microsatellite map of wheat. Genetics 149:2007-2023.

48. Rosielle, A. A. 1972. Sources of resistance in wheat to speckled leaf blotch caused by Septoria tritici. Euphytica 21:152-161.

49. Simon, M. R., and Cordo, C. A. 1998. Diallel analysis of four resistance components to Septoria tritici in six crosses of wheat (Triticum aestivum). Plant Breed. 117:123-126. 
50. Singh, R. P., and Rajaram, S. 1993. Genetics of adult-plant resistance to stripe rust in 10 spring bread wheats. Euphytica 72:1-7.

51. Stephenson, P., Bryan, G., Kirby, J., Collins, A., Devos, K., Busso, C., and Gale, M. 1998. Fifty new microsatellite loci for the wheat genetic map. Theor. Appl. Genet. 97:946-949.

52. Stewart, C. N., and Via, L. E. 1993. A rapid CTAB DNA isolation technique useful for rapid fingerprinting and other PCR applications. Biotechniques 14:748-750.

53. Tavella, C. M. 1978. Date of heading and plant height of wheat cultivars, as related to Septoria leaf blotch damage. Euphytica 27:577-580.

54. Thomas, W. T. B., Powell, W., Waugh, R., Chalmers, K. J., Barua, U. M., Jack, P., Lea, V., Forster, B. P., Swanston, J. S., Ellis, R. P., Hanson, P. R., and Lance, R. C. M. 1995. Detection of quantitative trait loci for agronomic, yield, grain and disease characters in spring barley (Hordeum vulgare L.). Theor. Appl. Genet. 91:1037-1047.

55. Van Beuningen, L. T., and Kohli, M. M. 1990. Deviation from the regression of infection on heading and height as a measure of resistance to Septoria tritici blotch in wheat. Plant Dis. 74:488-493.
56. Van Ginkel, M., and Rajaram, S. 1993. Breeding for durable resistance to diseases in wheat: An international perspective. Pages 258-279 in: Durability of Disease Resistance. T. H. Jacobs and J. E. Parlevliet, eds. Kluwer Academic Publishers, The Netherlands.

57. Van Ooijen, J. W. 1999. LOD significance thresholds for QTL analysis in experimental populations of diploid species. Heredity 83:613-624.

58. Vos, P., Hogers, R., Bleeker, M., Reijans, M., Vandelee, T., Hornes, M., Frijters, A., Pot, J., Peleman, J., Kuiper, M., and Zabeau, M. 1995. AFLP - a new technique for DNA fingerprinting. Nucleic Acids Res. 23:4407-4414.

59. Yu, D. Z., Yang, X. J., Yang, L. J., Jeger, M. J., and Brown, J. K. M. 2001. Assessment of partial resistance to powdery mildew in Chinese wheat varieties. Plant Breed. 120:279-284.

60. Zhang, X., Haley, S. D., and Jin, Y. 2001. Inheritance of Septoria tritici blotch resistance in winter wheat. Crop Sci. 41:323-326.

61. Zhang, Z. J. 1995. Evidence of durable resistance in nine Chinese land races and one Italian cultivar of Triticum aestivum to Puccinia striiformis. Eur. J. Plant Pathol. 101:405-409. 